IZA DP No. 4252

The US Inflation-Unemployment Tradeoff:

Methodological Issues and Further Evidence

Marika Karanassou

Hector Sala

June 2009 


\title{
The US Inflation-Unemployment Tradeoff: Methodological Issues and Further Evidence
}

\author{
Marika Karanassou \\ Queen Mary, University of London \\ and IZA \\ Hector Sala \\ Universitat Autònoma de Barcelona \\ and IZA
}

Discussion Paper No. 4252

June 2009

IZA

P.O. Box 7240

53072 Bonn

Germany

Phone: +49-228-3894-0

Fax: +49-228-3894-180

E-mail: iza@iza.org

\begin{abstract}
Any opinions expressed here are those of the author(s) and not those of IZA. Research published in this series may include views on policy, but the institute itself takes no institutional policy positions.

The Institute for the Study of Labor (IZA) in Bonn is a local and virtual international research center and a place of communication between science, politics and business. IZA is an independent nonprofit organization supported by Deutsche Post Foundation. The center is associated with the University of Bonn and offers a stimulating research environment through its international network, workshops and conferences, data service, project support, research visits and doctoral program. IZA engages in (i) original and internationally competitive research in all fields of labor economics, (ii) development of policy concepts, and (iii) dissemination of research results and concepts to the interested public.
\end{abstract}

IZA Discussion Papers often represent preliminary work and are circulated to encourage discussion. Citation of such a paper should account for its provisional character. A revised version may be available directly from the author. 


\section{ABSTRACT}

\section{The US Inflation-Unemployment Tradeoff: Methodological Issues and Further Evidence*}

This paper addresses the various methodological issues surrounding vector autoregressions, simultaneous equations, and chain reactions, and provides new evidence on the long-run inflation-unemployment tradeoff in the US. It is argued that money growth is a superior indicator of the monetary environment than the federal funds rate and, thus, the focus is on the inflation/unemployment responses to money growth shocks. SVAR (structural vector autoregression) and GMM (generalised method of moments) estimations confirm earlier findings in Karanassou, Sala and Snower (2005, 2008b) obtained from chain reaction structural models: the slope of the US Phillips curve is far from vertical, even in the long-run, which implies that the nominal and real sides of the economy are symbiotic. In the light of the significant and robust long-run inflation-unemployment tradeoffs, policy makers should reconsider the classical dichotomy thesis.

JEL Classification: E24, E31, E51

Keywords: inflation, unemployment, money growth, SVAR, GMM, structural modelling, chain reactions

Corresponding author:

Hector Sala

Departament d'Economia Aplicada

Universitat Autònoma de Barcelona

08193 Bellaterra

Spain

E-mail: hector.sala@uab.es

\footnotetext{
* Hector Sala is grateful to the Spanish Ministry of Education and Science for financial support through grant SEJ2006-14849/ECON.
} 


\section{Introduction}

The extent to which movements in output and unemployment depend on monetary fluctuations is a crucial issue in today's macroeconomics. Of particular interest, in this context, is to know how nominal magnitudes (such as the price level or money supply) interact with real economic activity and how this interaction evolves with the passage of time. The conventional wisdom supports the classical dichotomy and the absence of an inflationunemployment tradeoff in the long run, i.e. the slope of the Phillips Curve (PC) is vertical in the long run.

The main objective of our work is to provide further evidence on the long-run relationship between inflation and unemployment for the US. This evidence is based on new estimates of the slope of the PC using two popular econometric techniques, structural vector autoregression (SVAR) and generalised method of moments (GMM), and supports previous results obtained through the estimation of dynamic multi-equation structural models. We refer, in particular, to the downward sloping PC documented for the US in Karanassou, Sala and Snower $(2005,2008 b)$ over the 1966-2000 and 1963-2005 periods. The main contribution of our paper is thus to assess the robustness of these existing results using different empirical procedures. Furthermore, we provide a systematic compare and contrast discussion of the various methodological issues associated with the above econometric approaches, and highlight their respective pros and cons. This discussion is necessary in view of the common assertion that "There is as yet little certainty about how best to specify an empirically adequate model of aggregate fluctuations." (Woodford, 2009, p. 275).

In the context of dynamic multi-equation systems (like SVARs and "structural" models), the inflation-unemployment tradeoff can be measured by the ratio of inflation and unemployment responses to a monetary policy shock. In turn, in the context of single equations (like the hybrid new Keynesian PC model), this tradeoff is measured by the short- and longrun sensitivities of inflation to the unemployment rate. In both cases, the Phillips curve can be regarded as a function that, given a monetary policy shock, translates the impulse response function (IRF) of unemployment into the IRF of inflation and vice versa (Mankiw, 2001). Therefore, to evaluate the tradeoffs between nominal and real developments it is crucial to identify the relevant monetary policy shock.

We proxy monetary policy by the growth rate of money supply because we believe money growth is a better indicator of the overall monetary conditions than the federal funds rate. This is a controversial issue, and the literature has argued both in favour of (Nelson, 2003, 2008; Reynard, 2007; Favara and Giordani, 2009) and against (Estrella and Mishkin, 1997; Woodford, 2003, 2008) the role played by money supply in the conduct of monetary policy. In Section 2 we argue that the monetary environment is better described by money growth than the widely used federal funds rate, since money growth reflects not simply the level of the yield curve but its slope and curvature as well. Furthermore, Nelson (2008, p. 1797), 
among other studies, defends "the proposition that money growth does actually determine inflation in the long run". Consequently, in what follows we consider money growth shocks as the impulses that propagate the time-varying responses of the inflation and unemployment rates within a SVAR (or any dynamic multi-equation) model, and money growth as an instrument in the GMM estimation of the Phillips curve slope.

Karanassou, Sala and Snower (2005, 2008b), KSS hereafter, investigate the inflationunemployment tradeoff using dynamic multi-equation models which feature spillover effects. They call their framework of analysis the chain reaction theory (CRT) and distinguish it from the traditional dynamic simultaneous equations (SE) framework which stems from the Cowles commission program. In contrast to the latter, CRT models focus on dynamics and flourish in a distributed-lag environment, placing emphasis on the role of IRFs. While dynamics and IRFs are also focal points in the (S)VAR framework, there are also crucial differences between CRT and (S)VAR models that will be discussed in the course of the paper.

As shown in Section 3, in a simultaneous equation model mere inspection of the individual equations only gives the short-run sensitivities ${ }^{1}$ of the endogenous variables with respect to the exogenous ones. CRT calls these sensitivities "local" and distinguishes them from the "global" ones, which are influenced by the inherent feedback mechanisms due to spillover effects (i.e. the simultaneity element). "Global" sensitivities can be adequately measured by the system's IRFs: the contemporaneous responses give the short-run "global" sensitivities, while the cumulative IRFs give the long-run "global" sensitivities (see Karanassou, Sala and Snower, 2008b). The reason that CRT models refer to the inherent 'simultaneity' issue as 'spillovers' is to emphasise the plethora of feedback mechanisms contained in the system of equations, and flag their role in the measurement of the "global" sensitivities. The problem with the traditional SE estimates is that although they may seem reasonable if we take them at face value ("local" estimates), they might be misleading due to spillovers, in which case we need to look at the "global" estimates.

In other words, the "global" sensitivities offer an additional diagnostic tool for the estimated system of simultaneous equations, since the economic plausibility of the signs and magnitudes of the overall system's slopes/elasticities serves to diagnose the estimated model. The implication is that, although certain exogenous variables are significant in the respective equations of a labour market model, IRF analysis might reveal that they contribute minimally to the trajectory of the unemployment rate over a given sample period. ${ }^{2}$ We believe that a crucial factor which led to the disillusionment with the macroeconometric SE

\footnotetext{
${ }^{1}$ Depending on the specific form of the variables in the equation under examination (linear or logarithmic), these sensitivities may refer to elasticities, semi-elasticities, or slopes.

${ }^{2}$ For example, Karanassou and Sala (2009) estimate a labour market system for Australia over the $1972-$ 2006 period and find that financial wealth affects significantly labour demand, while working-age population affects significantly labour supply. Nevertheless, IRF analysis of the univariate representation of the system shows that the unemployment contributions of these variables are minimal.
} 
models, very popular in the past, was the lack of such a diagnosis. In sharp contrast to the SE models but in line with the CRT, such a diagnosis is a built-in feature of the (S)VAR methodology, since it relies on the IRFs of its closed systems. It is thus worth pointing out that, since the IRFs play a key role in dealing with the simultaneity element, the CRT can be regarded as an improvisation and synthesis of the SE and VAR approaches.

Although both the CRT and (S)VAR procedures focus on the responses to impulses (shocks) and evaluate the "global" sensitivities of the variables under examination, they significantly deviate in how they depict an impulse: in the (S)VAR system shocks (impulses) arise from its error terms, while in the CRT system "shocks" refer to the actual changes in the exogenous variables. Therefore, an advantage of the CRT approach over the SE and (to a lesser extent) SVAR approaches is that the identification of policy effects is not a problem. ${ }^{3}$

On a different note, CRT and SE models are generally considered to be "structural", whereas VARs are generally regarded as "atheoretical". The concept of structural is open to different interpretations and thus its definition is contestable rather than unanimous. We assign the "structural" attribute to our CRT system as long as we are convinced that it applies to and explains the real world. In this spirit the CRT approach develops dynamic structural models with spillovers aiming at yielding insight into the economic developments.

Nevertheless, we should emphasise that the CRT approach does not fall into the murky waters of the theoretical versus data-driven debate, since its models rely on the bidirectional feedback between a prior viewpoint and the observations-driven analysis. Put it differently, the CRT methodology investigates the interplay between theory and evidence, rather than compartmentalising them. Since the CRT equations are driven by this interplay, they cannot be simply regarded as loose interpretations of economic theory. This "holistic" nature of the CRT approach distinguishes it from the (S)VAR and SE macroeconometric methodologies, which, instead, aim at bridging the gap between theory and data.

In the empirical literature there is growing evidence that inflation and unemployment are interrelated in the long-run. For the US, Favara and Giordani (2009) estimate VARs on quarterly data and find that shocks to monetary aggregates contain substantial information on the future paths of output, prices and the interest rate. Ribba (2006) identifies a structural VECM and finds that permanent supply shocks explain the long-run comovement of inflation and unemployment in the US. These studies reinforce the findings of Campbell and Mankiw (1987) who estimate long-lasting real GDP responses to monetary disturbances using ARIMA models. Karanassou, Sala and Snower (2005 and 2008b) and Karanassou and Sala (2008) apply the CRT methodology and find that the US inflation-unemployment tradeoff in the long-run is between -3.5 and -3.7. This implies that a, say 10 percentage points

\footnotetext{
${ }^{3} \mathrm{SE}$ models were heavily criticised for the large number of incredible identifying assumptions, implicit in their structure. It is rather ironic that the SVARs have recently faced a similar critique (Section 3.1 discusses this issue).
} 
(pp), increase in inflation (due to a permanent $10 \mathrm{pp}$ increase in money growth) would reduce the unemployment rate by approximately 2.7-2.9 pp in the long-run.

In the context of a SVAR model for Spain, Dolado, López-Salido and Vega (2000) experiment with three alternative identifying assumptions to estimate the long-run tradeoff between inflation unemployment. In the monetarist scenario, where there is no long-run impact of supply shocks on the level of inflation, i.e., inflation is a demand (monetary) phenomenon in the long-run, they find that the slope of the long-run Phillips curve is -3.33. In the context of a CRT model, Karanassou, Sala and Snower (2008a) find it to be flatter, around -2.7. Also for Spain, Bajo-Rubio, Díaz-Roldán and Esteve (2007) estimate backward-looking Phillips curves, test endogenously for multiple structural breaks, and find a stable long-term tradeoff between inflation and the level of economic activity. For Italy, and also in a SVAR context, Ribba (2007) uncovers the influence of the monetary policy on the long-run movements in unemployment. In turn, Karanassou, Sala and Snower (2003) use a CRT model for the EU and find that the slope of the long-run Phillips curve is -3.2.

In the GMM literature of the new Phillips curve, it is common practice to restrict to unity the sum of the coefficients on the lead and lagged inflation terms. Since this is consistent with the conventional wisdom of a long-run vertical Phillips curve, not much attention is placed on testing such a restriction. In contrast, Karanassou, Sala and Snower (2003) estimate a standard hybrid single-equation Phillips curve by GMM for the EU without imposing this a-priori restriction. They find a long-run inflation-unemployment tradeoff between -3.1 and -3.5 (depending on the specific instrument list), which confirms their estimate of the long-run PC slope obtained through the CRT methodology.

In Section 4 we contribute to the inflation-unemployment tradeoff literature by estimating the slope of the PC in the US using the SVAR and GMM methodologies, respectively. Our SVAR application is in line with the three-variable VAR model of Stock and Watson (2001) featuring inflation and unemployment, but with money growth instead of the federal funds rate. We estimate the $\mathrm{PC}$ slope by computing the impulse-response functions of inflation and unemployment to a money growth shock, and obtain a long-run tradeoff of -2.57 . In turn, the GMM estimation of a standard hybrid specification of the new Phillips curve uses unemployment as the driving force variable and gives a long-run $\mathrm{PC}$ slope ranging from -3.30 to -4.32 . Therefore, the SVAR and GMM estimates reinforce the robustness of a significant long-run inflation-unemployment tradeoff in the US.

The rest of the paper is structured as follows. Section 2 discusses the advantages of money growth as an indicator of the overall monetary conditions, and overviews the robustness of the nonvertical PC within the CRT framework. Section 3 reflects on the salient features of the SE, SVAR and CRT methodologies, and uses an analytical illustration to uncover their differences and similarities. Section 4 presents the SVAR and GMM estimations of the long-run inflation-unemployment tradeoff. Section 5 concludes. 


\section{Money Growth and the Phillips Curve}

\subsection{Money Growth as a Proxy of Monetary Conditions}

The Phillips curve function traces the comovements of inflation and unemployment originated by changes in the monetary conditions. Here we evaluate the inflation-unemployment tradeoff by examining the time-varying responses of inflation and unemployment with respect to a parallel shift in the growth trajectory of money supply. This has a clear advantage for measuring the slope of the long-run PC, since a permanent shock in the growth rate of money is associated with changes in the long-run inflation and unemployment rates.

Our view is that another advantage of money growth is that it is a better proxy of the overall monetary conditions than the federal funds rate, since it reflects not only the level of the yield curve (i.e. short-term interest rate), but also its slope (i.e. spread) and curvature (i.e. relative spread). ${ }^{4}$ The following developments, which can be observed in Figure 1, are supportive of this thesis. First, consider the higher spreads and monetary contraction (decrease in money growth) of the 1980s. Second, the mid/late 1990s witnessed a flattening yield curve, a relatively stable federal funds rate and a monetary expansion. In addition, increases (decreases) in the short-term rate do not always reflect monetary contractions (expansions). For example, the increase in the fund rate from 3\% in 1993 to $6 \%$ in 1995 was accompanied by an increase in money growth from $1.5 \%$ to $4 \%$ and strong economic growth.

Furthermore, money growth captures the fluctuations in the liquidity of the market and the surrounding regulatory framework. To illustrate this point, recall that after the 1987 stock market crash, the Fed provided additional reserves to the banking system to prevent a liquidity squeeze (Taylor, 1993). Following the 1988-89 crisis in the savings and loan industry, banks restricted their lending to conform to new regulations that would minimise the chances of another crisis and bailout in the future. The Fed's decision to treat long-term government bonds as if they were perfectly safe (despite their high sensitivity to interest rate changes) encouraged banks to invest in these bonds rather than lend to businesses, and thus further precipitated the 1991 recession (Stiglitz, 2003, p. 40).

The plots in Figure 1 indicate that money growth reflects rather well the monetary policy environment. Observe, for example, that before 1979 there is a clear negative relationship between the (short) interest rate and money growth. In the 1980's this breaks down. Also, the pre-Volcker era is characterised by mostly negative spreads and a positive relationship between money growth and the spread. Over the 1980-1993 period, the spreads are mostly positive and a steeper yield curve is accompanied by a monetary contraction. Now consider the Clinton years 1993-2000: the federal funds rate hardly changes, whereas the spread

\footnotetext{
${ }^{4}$ It is generally argued that the shape of the yield curve is influenced by expected future spot rates which, in turn, are influenced by monetary policy. Furthermore, Estrella and Mishkin (1996) show that monetary policy affects the yield curve spread which, in turn, affects real economic activity.
} 
significantly decreases. Figure 1a shows that this flattening of the yield curve is captured by an increasing money growth. According to Stiglitz (2003), the decrease in the long-term interest rates was due to the budget deficit reduction. Nelson (2003) argues that money may act as proxy for various yields that drive aggregate supply and thus affect output. Favara and Giordani (2009), using a VAR with US quarterly data from 1966.01 to 2001.03, show that money may proxy, apart from the short-term interest rate, a term spread (3 months-10 years) as well.

Figure 1. Money growth and the yield curve

a. Money growth and the yield curve slope

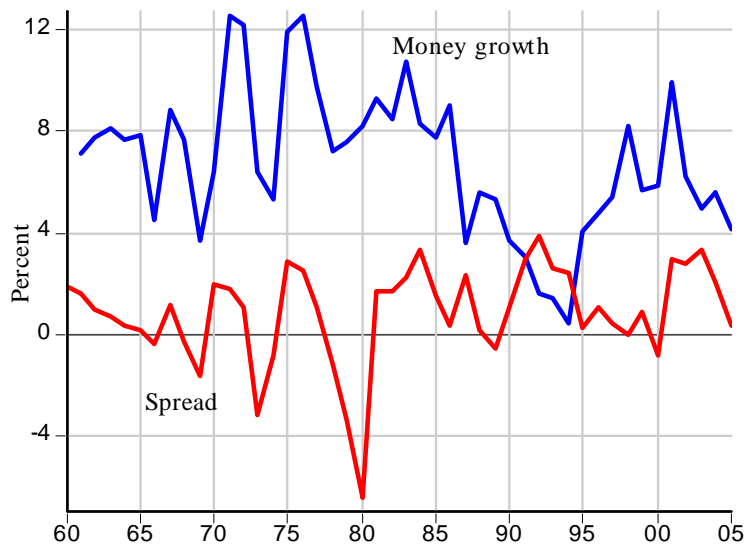

b. Money growth and the Federal Funds rate

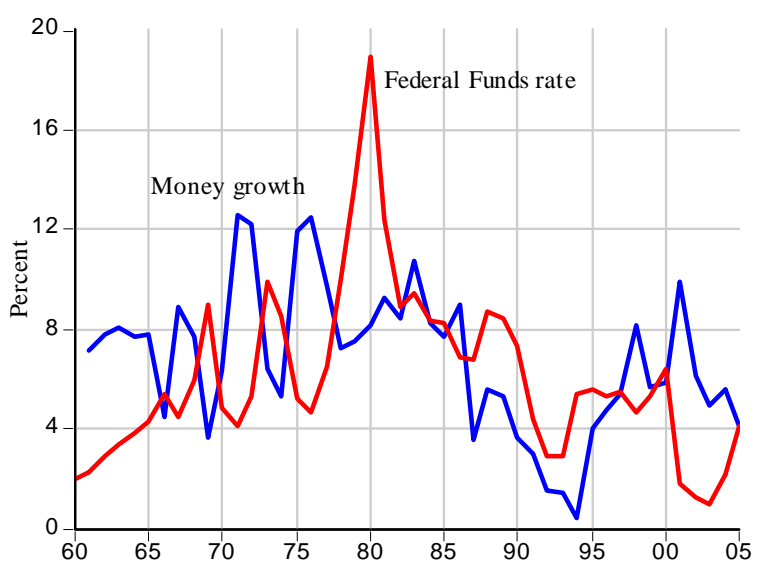

Notes: Spread is the difference between the long-term interest rate (10-year government bond yield) and the federal funds rate [Source: Federal Reserve Board]. Money growth is the growth rate of money sup ply, broad definition [Source: OECD, EO84 (2008, vol. 2)].

Although the mechanism by which a monetary expansion/contraction is generated is beyond the scope of this study, some clarifications are important. First, a monetary expansion (an increase in money growth) can arise when the Fed lowers the short-term interest rate and/or there are changes in the banking regulations. In either case money growth movements simply reflect changes in monetary policy. Second, fiscal measures or a mixture of monetary and fiscal policies can affect the slope of the yield curve, i.e. the spread between long- and short-term interest rates, which can be captured by the growth rate of money.

The dominant monetary policy prescription of the so called new consensus macroeconomics focuses on the role of interest rates in controlling inflation in a vertical PC setting. ${ }^{5}$ Nevertheless, we should stress that a number of prominent authors have argued that monetary aggregates are important for policy making. For example, Nelson (2007, p. 1476) states that "the intertwined positions that money growth pins down inflation in the longrun, and that the central bank cannot treat the nominal interest rate as an instrument in

\footnotetext{
${ }^{5}$ See Arestis and Sawyer $(2005,2008)$ for an appraisal of the new consensus in macroeconomics.
} 
the long-run, have been supported by monetary economists who have also served as leading policy makers." ${ }^{6}$ In addition, Reynard (2007) documents the importance of monetary aggregates and the inadequacy of short-term interest rates in modelling the evolution of inflation. Responding to Woodford's critique, ${ }^{7}$ Nelson (2008) further argues that, since monetary authorities cannot affect long-run interest rates due to neutrality, money growth is a variable that the central bank can use as an instrument in the long run.

Finally, Favara and Giordani (2009) are among several recent studies that, as Nelson (2008, p. 1794) points out, "have established that money has explanatory power for output and inflation beyond what the standard New Keynesian model predicts money should have, and exhibits this power across a number of different monetary policy regimes." In particular, Favara and Giordani (2009) argue that the standard monetary policy models of recent years have downplayed the role of monetary aggregates. Estimating a VAR for the US, they find that shocks to broad monetary aggregates influence the future trajectories of output, prices and interest rates. Finally, Mankiw and Reis (2002), Chari, Kehoe, and McGrattan (2000), Cooley and Quadrini (1999), and Cooley and Hansen (1989), among others, assume that the monetary policy shock is the error in the time series representation of money growth.

\subsection{The Long-run Inflation-Unemployment Tradeoff}

As noted in the introduction, the evidence supporting the idea that the nominal and real sides of the economy are interrelated even in the long-run has been growing in recent years. The CRT has contributed to this literature by performing different analyses on the basis of Mankiw's (2001) assertion that the PC is a function that translates the IRF of unemployment into the IRF of inflation (and vice-versa) in response to a monetary policy shock. Accordingly, the slope of the $\mathrm{PC}$ is measured by the ratio of the inflation and unemployment responses to a permanent shift in money growth. As we argued above, the use of money growth (as opposed to a short-term interest rate) helps us to better assess the impact of a change in the monetary conditions on the variables of interest.

For the US in particular, Karanassou, Sala and Snower (2008b) evaluated the long-run slope of the Phillips curve at -3.5. They estimated a dynamic macro-labour system with spillover effects over the 1960-2005 period comprising (i) wage and price setting equations on its nominal side, and (ii) labour demand and supply, productivity, and financial wealth equations on its real side. Also in the context of the CRT methodology, the robustness of the result of a downward-sloping long-run PC is demonstrated in Karanassou, Sala and Snower (2005), and Karanassou and Sala (2008) who find long-run slopes of -3.7 and -3.6, respectively. ${ }^{8}$

\footnotetext{
${ }^{6}$ Bernanke, Goodhart, and Mishkin are among them.

${ }^{7}$ See the Journal of Money, Credit and Banking, Vol. 40, No 8 (December 2008) for (i) the critique by Woodford on the issue with particular reference to Nelson (2003), and (ii) Nelson's response.

${ }^{8}$ The CRT models in KSS (2008b) and KS (2008) are expanded and augmented versions of the three-
} 
In what follows we further validate econometrically the above finding by showing that a long-run inflation-unemployment tradeoff can also be obtained via the application of the SVAR and GMM econometric techniques to a semi-annual dataset covering the same (1960$2005)$ period. It is worthwhile noting that the SVAR and GMM models we estimate in Section 4, and the CRT ones of our earlier papers, satisfy the money neutrality (no money illusion) assumption: a change in money growth leads to an equiproportionate inflation change in the long-run. This is in line with the definitions of long-run neutrality and superneutrality asserted by Fisher and Seater (1993, p. 405). Specifically, long-run neutrality is the proposition that a permanent, exogenous change in the level of money supply does not affect the level of real variables (and the nominal interest rate) and leads to an equiproportionate change in the level of prices (and other nominal variables) in the long run. In turn, long-run superneutrality is the proposition that a permanent, exogenous change in the growth rate of money supply does not affect the level of real variables in the long run (and leads to an equal change in the nominal interest rate).

The finding of a downward-sloping long-run PC puts the CRT framework of analysis in sharp contrast to the monetarist viewpoint, which claims that monetary factors are the sole driving force of inflation. The existence of an inflation-unemployment tradeoff in the long-run, due to the interplay of money growth and nominal frictions, differentiates the CRT approach from the monetarist one, since it implies that the driving forces of inflation and unemployment can be jointly identified. This means that the driving forces of inflation, are determined by the diverse exogenous variables (not only the monetary ones) of the CRT model under examination. In this context, the estimated model in KSS (2008b) provides an all-encompassing framework where the evolution of inflation and unemployment are interwoven. This holistic model allows the performance of the US economy during the roaring nineties to be appraised using counterfactual simulations or, in Sims' jargon, 'innovation accounting' (Qin, 2008). Specifically, counterfactual simulations of the empirical CRT model, where each exogenous variable was fixed at its 1993 value from 1993 to 2000 (while the rest were on their actual trajectories), showed that a number of factors influenced the time paths of unemployment and inflation over the 1993-2000 period. On one hand, the increase in money growth put upward pressure on inflation and substantially lowered unemployment. On the other, the rise in productivity growth, the budget deficit reduction, and the increase in the trade deficit put downward pressure on inflation and had a modest impact on the unemployment rate.

In what follows we deal with the various methodological issues regarding the estimation of the Phillips curve slope and present the SVAR and GMM results.

equation system in KSS (2005), which comprises wage setting, price setting, and unemployment rate equations. Whereas KSS (2008b) endogenise productivity and financial wealth, and derive the unemployment rate from labour supply and demand equations, Karanassou and Sala (2008) endogenise capital accumulation. 


\section{Methodological Issues}

Before we proceed with the estimated structural VAR model and the associated inflationunemployment tradeoff, it is vital to discuss the salient features of the simultaneous equations (SE), vector autoregressions (VARs), and chain reaction theory (CRT) macro models, and point out their differences and similarities. ${ }^{9}$

\subsection{Reflections on Simultaneous Equations, Vector Autoregres- sions, and Chain Reactions}

Dynamic multi-equation systems are the common ground of the SE, (S)VAR, and CRT approaches to macro modelling. While VARs are generally characterised as atheoretical, SE and CRT models fall under the umbrella of structural approaches. An in-depth discussion of whether SE (and chain reaction) models are indeed "structural", and whether "atheoretical" VARs is a misnomer rather than a fair description is beyond the scope of this study. An interesting account and intelligible discussion of the rise of VARs can be found in Qin (2008).

Estimation of SE and CRT models involves the selection of the exogenous variables and the number of lags to be included in each equation of the system. Since these are mostly judgmental decisions, the above methodologies rely heavily on discretion rather than simple mechanical rules. On the other hand, the advantage of SE and CRT modelling is the economic intuition and plausibility that accompanies each of the estimated equations. Both procedures have thus the potential of explaining the economic developments and can measure the contribution of the various exogenous variables to the evolution of the endogenous ones. The major drawback of the traditional multi-equation macroeconometric models (SE) has been their poor predictions, and thus their misleading policy guidelines, especially during the macroeconomic turbulence of the 1970s.

An important factor behind the quite often disastrous performance of the SE methodology is that, unless the IRFs of the endogenous variables are computed, the researcher cannot obtain the "global" short- and long-run sensitivities with respect to the exogenous variables in the model. The individual equations of the system only display the "local" short-run sensitivities of an exogenous variable. However, the simultaneity element of the system gives rise to spillovers which can affect both the size and the sign of the slopes or elasticities. KSS (2008) demonstrate how to derive the global short- and long-run sensitivities in a dynamic model with inter-equation spillovers. These are essentially measured

\footnotetext{
${ }^{9}$ The SE model by Klein and Ball (1959) for the wage and price relationship is an archetypal example of the Cowles structural procedure: a dynamic system of (i) wage-rate, (ii) earnings-wage spread (or wage-drift), (iii) work hours, and (iv) CPI price (mark-up) equations. In turn, the VAR macroeconomic framework was pioneered by Sargent and Sims in their 1977 joint paper (Qin, 2008, p. 10). For a brief and comprehensive tutorial of the VAR procedure see Stock and Watson (2001). Finally, the CRT framework of analysis is surveyed in KSS (2009).
} 
by the contemporaneous and cumulative values of the IRF of an endogenous variable to a one-off unit change in a specific exogenous variable.

Compared to SE models, the value added of the CRT methodology is that the IRFs are a focal point in the analysis of its models. The global elasticities can be used as a misspecification tool since they can diagnose the economic plausibility of the model. We believe that the lack of such diagnosis was a major factor behind the disillusionment with the traditional macroeconometric modelling. The 'chain reaction' epithet flags the crucial role of IRFs in CRT model building. The importance of response functions to exogenous changes is further emphasised by the 'spillovers' label of simultaneity, an issue inherent in the equations of CRT models.

Unlike the SE and CRT frameworks, VAR models use an identical set of regressors and lag structure in the individual equations of their systems. Thus, simultaneity is not an issue and the VAR statistical toolkit is easy to use and interpret. Impulse response functions constitute the core of the VAR methodology, where the impulse (one-off shock) relates to the error term of a specific equation in the VAR model. Although IRF analysis is also at the core of the CRT methodology, the impulse in CRT models, in contrast to VARs, is a one-off change in a specific exogenous variable. Defining the impulse as a change in an exogenous variable rather than a shock to the error term of an equation has a clear twofold advantage. First, identification of policy effects is not a problem in CRT models, as it is in SE and VARs, since policy changes are associated with changes in the exogenous variables. Second, it gives rise to the "contributions" measure, which shows how an endogenous variable in the CRT model responds to the actual changes in an exogenous variable over a sample interval.

Therefore, the CRT methodology provides an improvisation and synthesis of the SE and VAR methodologies. It should be noted that the CRT methodology aims at explaining, rather than forecasting, the economic reality. Thus, in terms of its methodological association with the VAR setup, it proxies Sims' standpoint that the VAR approach was mainly developed for hypothesis testing and policy evaluation and contrasts Sargent's view that forecasting was the key objective of VARs (Qin, 2008). On one hand, the CRT macroeconometric model benefits from the analysis of IRFs and, on the other, it retains the economic substance of the relations embedded in the structural system. We further justify our thesis as follows.

A reduced form VAR model regresses each variable on its own lags and the lagged values of the other variables in the model. In this context, cross-equation correlation, due to correlation between the variables in the model, creates a problem in the calculation of the IRFs. The recursive VAR addresses this problem by including some contemporaneous values in the regressors list. ${ }^{10}$ Therefore, VARs are associated with a minimal amount of discretion - the main modelling decision involves the ordering of the variables in the recursive

\footnotetext{
${ }^{10}$ Since the estimation of the recursive VAR is based on the estimation of the reduced form VAR and the Cholesky decomposition of its covariance matrix, it produces uncorrelated residuals.
} 
model. Another advantage of the VAR methodology is that the overall influence of each variable on the rest of the system is gauged by the IRFs. It is important to point out that, although there is hardly any economic intuition underlying the ordering of the variables, the estimation results crucially depend on it. Consequently, VARs have been heavily criticized for their atheoretical (i.e. statistical rather than economic) nature.

Structural vector autoregressions (SVARs) addressed the critique against the atheoretical identification of the VAR equations by imposing an economic structure in the error terms. ${ }^{11}$ In other words, the SVAR methodology uses economic theory to decide on the contemporaneous correlations among the variables - hence, the "structural" adjective. ${ }^{12}$ Naturally, the models are adjusted until they give reasonable impulse response functions - this adjustment entails "nothing unscientific or dishonest" (see Leeper, Sims and Zha, 1996, p. 5).

The lack of attention to the individual equations of the (S)VAR model (estimated VAR coefficients go unreported) is due to the fact that (S)VAR equations do not have an economic interpretation. However, the interest equation in a monetary (structural) VAR model has a clear economic interpretation - it is the reaction function of the Fed (or central bank). Rudebusch (1998) argues that the shortcomings of the typical (S)VAR interest rate equation are a time-invariant linear structure, a restricted information set, the use of revised data, and long distributed lags. These features suggest that the standard VAR reaction function misrepresents endogenous monetary policy. ${ }^{13}$

Furthermore, Rudebusch (1998) suggests that (S)VARs should be improved by giving more weight to economic structure, and is critical of modelers who, under the excuse of "atheoretical econometrics", skip the standard misspecification tests. This critique against (S)VARs seems ironic in the light of Spanos (1990) argument that SE, even when each of their structural equations passes all diagnostic tests, still lack statistical adequacy if they do not satisfy the misspecification tests of the underlying reduced form VAR.

Finally, Leeper, Sims, and Zha (1996) argue that it is possible to construct economically interpretable SVAR models with superior fit to the data. In the discussion following this work (p. 69), Bernanke comments that by paying attention to identification, and thus becoming sophisticated, the new generation of VARs has "moved closer to the complex econometric models that were the subject of Sims's original critique." In addition, "Mankiw found it ironic that Sims, who had developed the VAR methodology to diminish the extent to which macroeconomic models rely on a tremendous number of what he had called incredible identifying assumptions on the structure, has, with his coauthors, had to return to making

\footnotetext{
${ }^{11}$ See, among others, Leeper, Sims, and Zha (1996), Rudebusch (1998), Christiano, Eichenbaum, and Evans (1999, 2005), Raddatz and Rigobon (2003), Dedola and Lippi (2005), and Ribba (2007).

${ }^{12}$ Note that a structural VAR may simplify to a recursive VAR - this structure is known as a Wold causal chain.

${ }^{13} \mathrm{Sims}$ notes that the issues of structural stability, linearity, and variable selection are not unique to VARs, and thus the critique by Rudebusch applies to all macroeconomic models. See the interesting exchange between Sims and Rudebusch in the International Economic Review (1998), vol. 39.
} 
many similar assumptions in order to identify policy effects." (Leeper, Sims, and Zha, 1996, p. 74).

In the light of the above discussion about the pros and cons of SE and (S)VAR models, it is worthwhile to emphasise the value added of the CRT methodology. Like SE models, the individual equations in CRT systems appeal to our economic reasoning. By deriving the univariate representations of the endogenous variables and the associated IRFs, the CRT approach ensures the plausibility of the estimated short- and long-run sensitivities. Thus, similarly to VARs, CRT models use the IRFs as a specification barometer and, consequently, can effectively measure the contributions of exogenous factors to the trajectories of the variables under investigation. ${ }^{14}$

Finally, we would like to stress that, while both the SE and (S)VAR methodologies aim at bridging (what they regard as) the compartmentalised areas of "theory" and data analysis, the CRT methodology focuses on the interplay of a prior viewpoint and observation-driven modelling in order to better understand the evolution of the economic magnitudes of interest.

\subsection{An Analytical Illustration of the SE, VAR and CRT Proce- dures}

We use a stylised macro-labour system to demonstrate the workings of the simultaneous equations, (structural) vector autoregressions, and chain reaction theory methodologies. For ease of exposition, we analyse a simple structural two-equation model of labour demand $\left(n_{t}\right)$ and real wages $\left(w_{t}\right)$ :

$$
\begin{aligned}
& n_{t}=\alpha_{1} n_{t-1}+\beta_{1} k_{t}-\gamma_{1} w_{t}+\varepsilon_{1 t}, \\
& w_{t}=\alpha_{2} w_{t-1}+\beta_{2} b_{t}+\gamma_{2} n_{t}+\varepsilon_{2 t},
\end{aligned}
$$

where the exogenous variables $k_{t}$ and $b_{t}$ denote capital stock and benefits, respectively; the autoregressive parameters are $0<\alpha_{1}, \alpha_{2}<1$, the elasticities $\beta$ s and $\gamma$ s are positive constants; and the error terms $\varepsilon_{1 t}, \varepsilon_{2 t}$ are uncorrelated strict white noise processes. (All variables are in logs.) It is worth noting that, by default, it is fruitless to examine the IRFs of the individual equations of a SE model. However, IRF analysis is feasible in the context of the underlying vector autoregressions.

The structural equations (1)-(2) can be reparameterised as a VAR model with exogenous variables:

$$
\begin{aligned}
& n_{t}=a_{11} n_{t-1}+a_{12} w_{t-1}+c_{11} k_{t}+c_{12} b_{t}+e_{1 t}, \\
& w_{t}=a_{21} n_{t-1}+a_{22} w_{t-1}+c_{21} k_{t}+c_{22} b_{t}+e_{2 t},
\end{aligned}
$$

\footnotetext{
${ }^{14}$ Needless to say, a battery of diagnostic tests and an adequate fit to data further reassure the statistical adequacy of the CRT model.
} 
where $e_{1 t}=\varepsilon_{1 t}-\gamma_{1} \varepsilon_{2 t}$, and $e_{2 t}=\gamma_{2} \varepsilon_{1 t}+\varepsilon_{2 t} ; a_{11}=\frac{\alpha_{1}}{1+\gamma_{1} \gamma_{2}}, a_{12}=\frac{-\gamma_{1} \alpha_{2}}{1+\gamma_{1} \gamma_{2}}, c_{11}=\frac{\beta_{1}}{1+\gamma_{1} \gamma_{2}}, c_{12}=$ $\frac{-\gamma_{1} \beta_{2}}{1+\gamma_{1} \gamma_{2}}, a_{21}=\frac{\gamma_{2} \alpha_{1}}{1+\gamma_{1} \gamma_{2}}, a_{22}=\frac{\alpha_{2}}{1+\gamma_{1} \gamma_{2}}, c_{21}=\frac{\gamma_{2} \beta_{1}}{1+\gamma_{1} \gamma_{2}}, c_{22}=\frac{\beta_{2}}{1+\gamma_{1} \gamma_{2}}$.

Observe that the error terms $\left(e_{1 t}, e_{2 t}\right)$ of the underlying VAR system (3)-(4) are correlated, since they are linear functions of the uncorrelated errors $\left(\varepsilon_{1 t}\right.$ and $\left.\varepsilon_{1 t}\right)$ of the structural SE system (1)-(2). Also note that the SE model (1)-(2) involves the estimation of six parameters, while the underlying VAR model (3)-(4) estimates eight parameters. This implies the following two cross-equation restrictions for the SE model:

$$
\begin{aligned}
& \frac{a_{21}}{a_{11}}=\frac{c_{21}}{c_{11}}=\gamma_{2}, \\
& \frac{a_{12}}{a_{22}}=\frac{c_{12}}{c_{22}}=\gamma_{1} .
\end{aligned}
$$

Application of Sargan's test ensures that the simultaneous equations (1)-(2) satisfy the above overidentifying restrictions.

Rewriting the simultaneous equations (1)-(2) as

$$
\begin{aligned}
\left(1-\alpha_{1} B\right) n_{t} & =\beta_{1} k_{t}-\gamma_{1} w_{t}+\varepsilon_{1 t}, \\
\left(1-\alpha_{2} B\right) w_{t} & =\beta_{2} b_{t}+\gamma_{2} n_{t}+\varepsilon_{2 t},
\end{aligned}
$$

where $B$ is the backshift operator, and further algebraic manipulation of the above leads to the univariate representations of employment and wages. That is, we can express each endogenous variable as a function of its own lags and the (contemporaneous and lagged values of the) exogenous variables in the system:

$$
\begin{aligned}
& {\left[\gamma_{1} \gamma_{2}+\left(1-\alpha_{1} B\right)\left(1-\alpha_{2} B\right)\right] n_{t}=\beta_{1}\left(1-\alpha_{2} B\right) k_{t}-\gamma_{1} \beta_{2} b_{t}+v_{1 t}} \\
& {\left[\gamma_{1} \gamma_{2}+\left(1-\alpha_{1} B\right)\left(1-\alpha_{2} B\right)\right] w_{t}=\beta_{2}\left(1-\alpha_{1} B\right) b_{t}+\gamma_{2} \beta_{1} k_{t}+v_{2 t}}
\end{aligned}
$$

where

$$
v_{1 t}=\left(1-\alpha_{2} B\right) \varepsilon_{1 t}-\gamma_{1} \varepsilon_{2 t}, \text { and } v_{2 t}=\left(1-\alpha_{1} B\right) \varepsilon_{2 t}+\gamma_{2} \varepsilon_{1 t} .
$$

We interpret the coefficients of the univariate representations of employment and wage dynamics (9)-(10) as the "global" sensitivities of the variables, as opposed to the "local" sensitivities which are obtained by simple eye inspection of the SE model (1)-(2). For example, the short-run "local" elasticity of employment with respect to capital stock is $\beta_{1}$ (see eq. (1)), whereas the short-run "global" elasticity is $\frac{\beta_{1}}{1+\gamma_{1} \gamma_{2}}$ (via eq. (9)). Note that the discrepancy between the "local" and "global" capital stock elasticities of labour demand is due to the spillover effect $\frac{1}{1+\gamma_{1} \gamma_{2}}$, which reflects the simultaneity of the structural equations (1)-(2); in this case, if the wage elasticity of labour demand or the (un)employment pressure on wages is zero $\left(\gamma_{1}=0\right.$ or $\gamma_{2}=0$, respectively), the two elasticities are identical. Generally, the difference between the "local" and "global" sensitivities is due to the spillover effects 
associated with the feedback mechanisms inherent in simultaneous equations. The value added of the CRT approach is using the univariate representations (9)-(10) to derive the time-varying responses of the system to "shocks", and evaluate the contributions of the exogenous variables to the evolution of the endogenous ones.

Since the VAR methodology focuses on the IRFs related to $e_{1 t}$ and $e_{1 t}$, it is vital to identify the impulses associated with the VAR error terms. The identification issue can by resolved by using an atheoretical ordering of the VAR equations or by relying on theory to engineer the structure of the error terms. The latter gives rise to the SVAR methodology. In sharp contrast, the CRT methodology, instead of focusing on the responses to shocks associated with some error term $(\varepsilon, e$, or $v)$, it examines the time-varying effects of the exogenous variables on the evolution of the endogenous variables. In other words, the CRT derives the IRFs by identifying shocks through the changes in the exogenous variables.

Naturally, the above illustrative dynamic system of employment and real wage equations (1)-(2) can be augmented by including nominal variables and enlarged with more equations.

\section{Empirical Evidence}

\subsection{SVAR Estimation of the Inflation-unemployment Tradeoff}

Since Bernanke and Blinder (1992), it is standard in monetary (S)VARs to use the federal funds rate to capture the US monetary policy. To disentangle the endogenous and exogenous components of this policy, Bernanke and Blinder regress the short-term interest rate on its own lags and the lags (and possibly contemporaneous values) of the other variables in the model. According to Bernanke and Blinder (1992), the federal funds rate provides a better measure of policy shocks than a monetary aggregate, since it is a good indicator of monetary policy and it "is probably less contaminated by endogenous responses to contemporaneous economic conditions than is, say, the money growth rate." However, as we argued in Section 2 , we believe that the overall monetary conditions of the economy are better described by the growth rate of a monetary aggregate than by a short-term interest rate. In addition, Rudebusch (1998) argues that one of the shortcomings of the (S)VAR literature is its failure to take into account the temporal instability of the Fed's reaction function.

Therefore, since our main objective is to determine whether a long-run inflation-unemployment tradeoff arises when there is a permanent monetary expansion/contraction, we use a structural VAR model that includes the unemployment rate, inflation, and money growth:

$$
A_{0} y_{t}=\sum_{i=1}^{p} A_{i} y_{t-i}+\varepsilon_{t}
$$

where $y_{t}^{\prime}=\left(u_{t}, \pi_{t}, \mu_{t}\right)$, the $A$ s are $(3 \times 3)$ coefficient matrices. This is analogous to the 
three-variable VAR model of inflation, unemployment, and the federal funds rate used by Stock and Watson $(2001)$. The $(3 \times 1)$ vector of error terms $\left(\varepsilon_{t}\right)$ has zero mean, constant variances, zero autocorrelations, and nonzero contemporaneous cross correlations:

$$
E\left(\varepsilon_{t}\right)=0, \text { and } E\left(\varepsilon_{t} \varepsilon_{s}^{\prime}\right)=\left\{\begin{array}{l}
C \text { for } t=s \\
0 \text { otherwise }
\end{array}\right\} .
$$

A popular identification assumption used in the literature to recover the structural parameters, $A$ s and $C$, is the recursiveness assumption. This implies that the errors are orthogonal, $C=I$, and the matrix of contemporaneous relations between the variables in the VAR is lower triangular:

$$
A_{0}=\left[\begin{array}{lll}
a_{u u} & & \\
a_{\pi u} & a_{\pi \pi} & \\
a_{\mu u} & a_{\mu \pi} & a_{\mu \mu}
\end{array}\right]
$$

Essentially the above identification scheme assumes that monetary developments take place contemporaneously with changes in the unemployment and inflation rates, while these variables react to monetary changes only with a lag. In other words, the monetary shock is orthogonal to these variables. Christiano, Eichenbaum, and Evans (1999) refer to this as the recursiveness assumption. ${ }^{15}$ It can be shown that this assumption, although not enough to identify the reactions of the variables to all the structural shocks, is sufficient to determine the responses of the macro variables to a monetary expansion or contraction. An appealing feature of the recursive identifying approach is that the ordering of the variables preceding (and following) the monetary variable does not affect the estimation of their IRFs to the monetary shock.

Estimation of the structural VAR model (12)-(14) gives the impulse response functions plotted in Figure 2. Although estimation of SVAR models commonly uses quarterly data, we use semi-annual time series to ensure that our dynamic regressions are free of $(\mathrm{G}) \mathrm{ARCH}$ effects. Using the Akaike Information Criterion we selected a VAR of lag order four. The sample period is 1963:1-2005:2, and the variables included in our equations are covariance stationary, I(0), according to KPSS tests. (These results are available upon request.) Note that, since our focus is the robustness of the inflation-unemployment tradeoff estimates under alternative econometric methodologies, we do not expand our dataset beyond the final estimation point in Karanassou, Sala and Snower (2008b), i.e. 2005.

Observe that the responses of unemployment and inflation are hump-shaped with peak

\footnotetext{
${ }^{15}$ Note that, while the recursiveness assumption is controversial, alternative identifying approaches are debatable as well. Furthemore, Christiano, Eichenbaum, and Evans (1999) explain that the adoption of alternative identification schemes does not necessarily imply that the monetary shock has a contemporaneous impact on unemployment and inflation.
} 
effects occurring after 1.5-2 years and 2-3 years, respectively. Also note that the above model is free from the price puzzle (i.e. a monetary contraction leads to higher inflation) that characterised the IRFs of monetary VARS. ${ }^{16}$

Figure 2. Responses to one standard deviation innovations in money growth
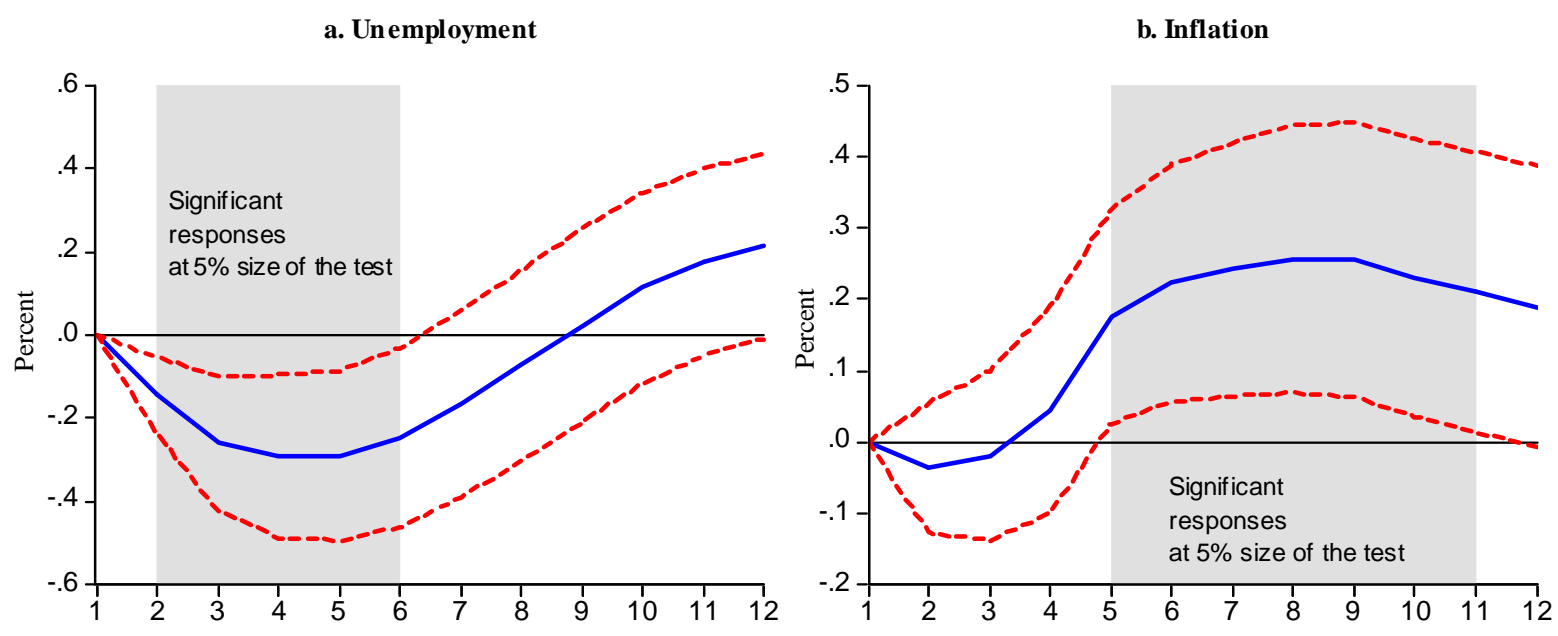

c. Money growth

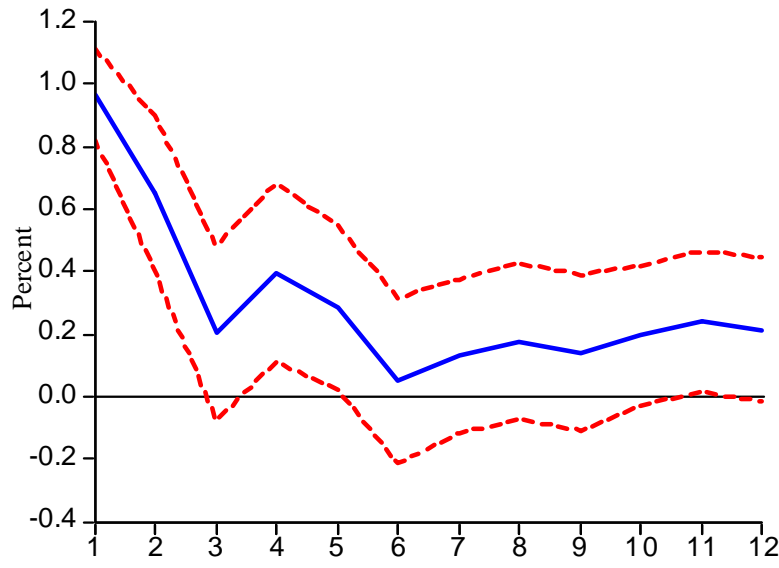

Note: the dotted lines give the $95 \%$ confidence interval.

Furthermore, variance decomposition analysis shows that around one third of the unemployment rate variation is explained by money growth, and the estimated parameters indicate that monetary policy is stabilising: a rise in unemployment increases money growth, while a rise in inflation decreases money growth (the slope coefficients are 0.52 and -0.49 , respectively).

Finally, we compute the long-run inflation and unemployment effects of a permanent shift in money growth as the sum of their significant responses to the one-off shock in money

\footnotetext{
${ }^{16}$ According to Sims (1992), the price puzzle arises from biased impulse responses due to omitted variables.
} 
growth. This is along the lines of Carlino and Defina (1998) who, in the context of SVARs, examine the effects of monetary policy across US regions by computing the cumulative IRF of real personal income to the fed funds shock. We find that the long-run slope of the Phillips curve is -2.57 with an "upper" bound equal to -14.6 and a "lower" bound equal to -0.33 , where the upper and lower bounds have been evaluated using the boundary values of the $95 \%$ confidence intervals of the inflation and unemployment responses.

\subsection{GMM Single-equation Estimation of the PC}

We continue by evaluating the inflation-unemployment tradeoff using the GMM in the context of the popular new (Keynesian) Phillips curve, NPC. Despite the lack of general consensus on the exact specification of the NPC, it is commonplace to use the following hybrid form:

$$
\pi_{t}=\beta^{f} E_{t} \pi_{t+1}+\beta^{b} \pi_{t-1}+\gamma^{\prime} x_{t},
$$

where $x_{t}$ is a column vector of forcing variables that includes a measure of excess demand (unemployment rate, output gap) or a measure of real marginal costs (such as the labour share in GNP), $E_{t}$ denotes conditional expectations, and the $\beta$ s and $\gamma \mathrm{s}$ are constants.

Following standard practice, expected future inflation is proxied by the lead of inflation and the above NPC is rewritten as

$$
\pi_{t}=\beta^{f} \pi_{t+1}+\beta^{b} \pi_{t-1}+\gamma^{\prime} x_{t}+\epsilon_{t+1},
$$

where the expectational error $\epsilon_{t+1}$ is proportional to $\left(E_{t} \pi_{t+1}-\pi_{t+1}\right)$, and is unforecastable at time $t$ under rational expectations. Much of the current literature is concerned with the question of whether the observed inflation autocorrelation results from backward-looking behaviour $\left(\beta^{f}=0\right)$ or forward-looking behaviour $\left(\beta^{b}=0\right)$ that is proxied by inflation lags.

Using a set of variables $z_{t}$ (dated $t$ and earlier) to instrument actual future inflation $\pi_{t+1}$, the NPC specification (16) can be consistently estimated by GMM or two-stage least squares. ${ }^{17}$ It is widely recognised that the empirical results of (16) are sensitive to (i) the choice and exact implementation of the estimation method, (ii) the forcing variables, (iii) the list of instruments, and (iv) the time span of the instruments, i.e. whether they are dated $t$ and earlier or $t-1$ and earlier. ${ }^{18}$

Furthermore, the exogeneity/endogeneity of the driving variables $x_{t}$ is of major importance. Bårdsen, Jansen and Nymoen (2004) argue that the derivation of the dynamic properties of inflation necessitates the analysis of a system that includes the forcing vari-

\footnotetext{
${ }^{17} \mathrm{GMM}$ requires the orthogonality condition $E_{t}\left[\left(\pi_{t}-\beta^{f} \pi_{t+1}-\beta^{b} \pi_{t-1}-\gamma^{\prime} x_{t}\right) z_{t}\right]=0$.

${ }^{18}$ These concerns are reminiscent of the instrumental variable estimation problems documented by Sargan (1964) who further argued that his own IV method does not have much value added vis-à-vis the simpler OLS one.
} 
ables as well as the rate of inflation, and conclude that the NPC (16) is inadequate as a statistical model. Finally, Arellano (2003) points out the problems associated with the tests of the orthogonality and relevance assumptions in instrumental variable models and the well known propensity of the $J$ test not to reject the overidentifying restrictions. ${ }^{19}$

Once again, although estimation of the Phillips curve with GMM is typically carried out with quarterly data, we use semi-annual time series to ensure that our standard hybrid single-equation PCs are free of (G)ARCH effects. The sample period is 1963:1-2005:2, and the variables included in our regressions are covariance stationary. (The results from the KPSS tests are available upon request.)

Table 1 presents the results for three different GMM models. All regressions are well specified, and the F-statistics show a strong correlation between the lead of inflation $\left(\pi_{t+1}\right)$ and the set of instruments (see Staiger and Stock, 1997). In addition, the chi-square test for overidentifying restrictions (J-statistic times the number of observations) indicates the validity of the instruments.

Further to the standard variables such as future inflation $\left(\pi_{t+1}\right)$, lagged inflation $\left(\pi_{t-1}, \pi_{t-2}\right)$, and unemployment $\left(u_{t}\right)$, we also use import prices $\left(i m p_{t}\right)$ to capture external nominal influences on prices. In particular, this variable takes into account the movements in oil prices, as well as the prices of other imported goods and services (for example, imports from China and East-Asia) which in recent decades have become increasingly important for the US economy. The relationship between inflation and import prices has been recently receiving close attention (Bean, 2007, for example). Also note that the growth rate of money $\left(\mu_{t}\right)$ is added to the list of instruments containing current and lagged values of the explanatory variables.

In the first specification the instruments are dated $t-1$ and earlier, whereas in the second one they are dated $t$ and earlier. The third specification differs from the second one as it does not include current unemployment in the instruments list. All three models give rise to a downward sloping long-run Phillips curve. The inflation-unemployment long-run tradeoff ranges from -3.30 to -4.32 . However, we should stress that - as in the rest of the literature in this area - our estimates crucially depend on the specification of the driving variables and instruments. Note that this tradeoffs are very close to the one we obtained via our structural modelling methodology. Finally, observe that in all three specifications the backward-looking behaviour has a stronger influence on inflation dynamics than the forward-looking behaviour.

\footnotetext{
${ }^{19}$ Thus he proposes a method for constructing tests of underidentification based on the structural form of the equation system. In the context of an augmented structural model, underidentification is defined by the imposed set of over-identifying restrictions and tested using standard statistical techniques.
} 


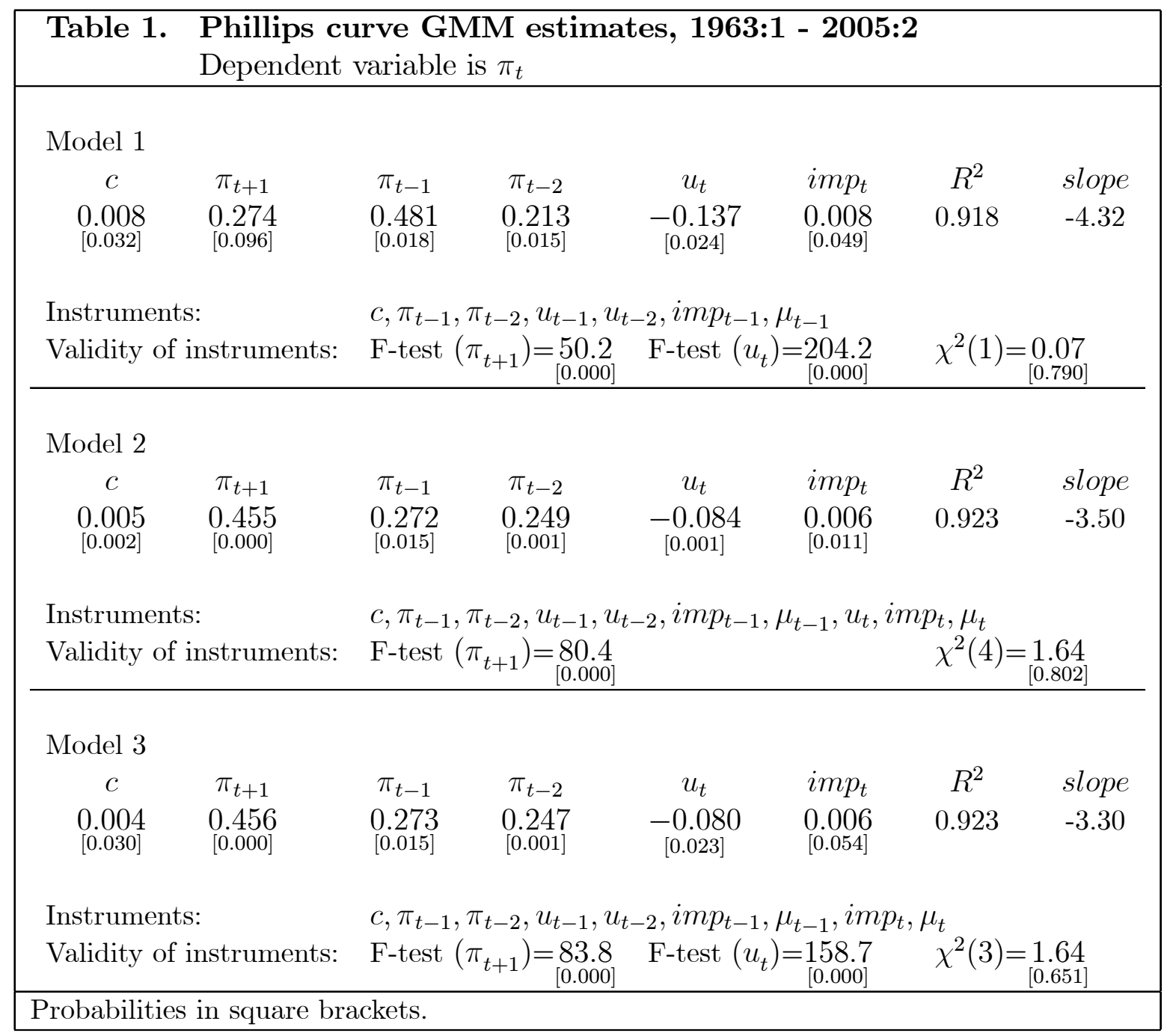

\section{Conclusions}

According to conventional wisdom an increase in the growth rate of money supply can have real effects only in the short run. In the long run, money growth will only increase inflation. This proposition of money superneutrality and the implied vertical long-run Phillips curve are being increasingly called into question. In this context, the value added of this paper is as follows.

First, we argued in favour of evaluating the time-varying slope of the $\mathrm{PC}$ as the ratio of inflation and unemployment responses to a permanent money growth shock, and strongly supported the view that money growth is a superior indicator of the monetary environment than the federal funds rate. Second, we uncovered the various methodological issues surrounding the alternative dynamic multi-equation models of the PC: vector autoregressions, simultaneous equations, and chain reactions. Finally, we contributed to the growing empirical literature on the inflation-unemployment tradeoff by applying the widely used SVAR and GMM econometric techniques. In particular, we assessed the robustness of a downward-sloping long-run PC obtained by a chain reaction structural model for the US 
over the 1963-2005 period. We estimated the long-run tradeoff in the range of -2.57 and -4.32 , which is in line with the findings of several studies for the US using different methodologies. Given the plethora of evidence against a vertical PC in the long-run, we conclude that policy makers should reappraise the classical dichotomy thesis.

Although we believe that the recent financial developments strengthen the position that money growth is a better proxy of the monetary environment than the federal funds rate, a word of caution is required regarding the degree to which money growth can capture the overall monetary conditions. As shown in Figure 3a, until the 3rd quarter of 2007 the rising money growth reflected the flattening of the yield curve and its eventual inversion (negative spreads). Nevertheless, since early 2008, money growth was unable to capture the exceptional circumstances of the financial crises (see Figures 3a-b).

Figure 3. Monetary de velopments from 2005 to 2008
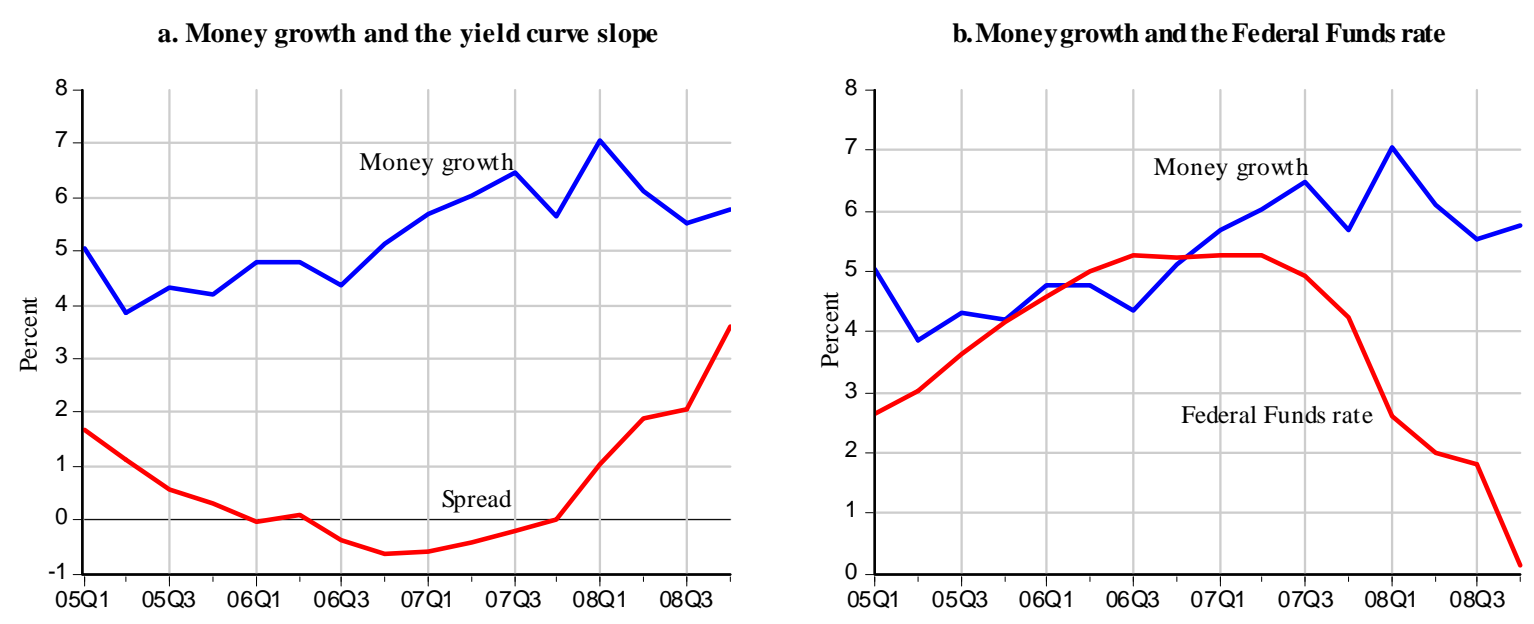

In the light of the current economic crisis the Fed has tried to stabilise the financial system using both 'qualitative' and 'quantitative easing' (Bagus and Schiml, 2009). While qualitative easing refers to changes in the structure of the central bank's balance sheet, quantitative easing refers to its lengthening. In its first stage, until the end of summer 2008, the financial crisis was associated with a failing subprime market to which the Fed responded through qualitative easing. In its second stage following the Lehman Brothers' bankruptcy, it became evident that the subprime crisis had mutated to a financial meltdown and the Fed resorted to quantitative easing as well. Furthermore, in their efforts to boost the seriously troubled banking system and revive the credit markets, monetary policy makers have taken several innovative actions which cannot be fully captured by money growth (let alone short-term interest rates).

We leave it to future research to explore how to quantify the recent unconventional monetary policies, the phenomenal rise of shadow banking in the 2000s, and their real impact regarding output and unemployment. 


\section{References}

[1] Arellano, M. (2003): Underidentification?, Presidential Address, XXVIII Simposio de Análisis Económico, Sevilla (a lecture from joint work with L. P. Hansen \& E. Sentana).

[2] Arestis, P. and Sawyer, M. (2005), "New Consensus Monetary Policy: An Appraisal", in Arestis, P., Baddeley, M. and McCombie, J. (eds.), The 'New' Monetary Policy: Implications and Relevance, Aldershot, Edward Elgar.

[3] Arestis, P. and Sawyer, M. (2008): "A critical reconsideration of the foundations of monetary policy in the new consensus macroeconomics framework", Cambridge Journal of Economics, vol. 32 , no. $5,761-779$.

[4] Bagus, P. and Schiml, M.H. (2009): "New modes of monetary policy: qualitative easing by the Fed", Economic Affairs, vol. 29, no. 2, 46-49.

[5] Bajo-Rubio, O., Díaz-Roldán, C. and Esteve, V. (2007): "Change of regime and Phillips curve stability: the case of Spain, 1964-2002", Journal of Policy Modeling, vol. 29, no. 3, 453-462.

[6] Bårdsen, G., E. Jansen, and R. Nymoen (2004): "Econometric evaluation of the New Keynesian Phillips curve", Oxford Bulletin of Economics and Statistics, vol. 66, no. s1, 671-686.

[7] Bean, C. (2007): "Globalisation and inflation", World Economics, vol. 8, no. 1, 57-73.

[8] Bernanke, B.S. and A.S. Blinder (1992): "The Federal Funds rate and the channels of monetary transmission", The American Economic Review, vol. 82, no. 4, 901-921.

[9] Campbell, J.Y. and Mankiw, N.G. (1987): "Are output fluctuations transitory?", The Quarterly Journal of Economics, vol. 102, no. 4, 857-880.

[10] Carlino, G. and DeFina, R. (1998): "The differential regional effects of monetary policy", The Review of Economics and Statistics, vol. 80, no. 4, 572-587.

[11] Chari, V.V., Kehoe, P.J., and McGrattan, E.R. (2000): "Sticky price models of the business cycle: can the contract multiplier solve the persistence problem?", Econometrica, vol. 68, no. $5,1151-1180$.

[12] Christiano, L.J., Eichenbaum, M., and C.L. Evans (1999): Monetary policy shocks: what have we learned and to what end?, pp. 65-148, in Woodford, M. and Taylor, J. (eds.), Handbook of Macroeconomics, vol. 1A, Amsterdam, New York and Oxford, Elsevier/North-Holland.

[13] Christiano, L.J., Eichenbaum, M., and C.L. Evans (2005): "Nominal rigidities and the dynamic effects of a shock to monetary policy", Journal of Political Economy, vol. 113, no. 1, $1-45$.

[14] Cooley, T.F., and G.D. Hansen (1989): "The inflation tax in a real business cycle model", The American Economic Review, vol. 79, no. 4, 733-748.

[15] Cooley, T.F., and V. Quadrini (1999): "A neoclassical model of the Phillips curve relation", Journal of Monetary Economics, vol. 44, no. 2, 165-193.

[16] Dedola, L., and F. Lippi (2005): "The monetary transmission mechanism: evidence from the industries of five OECD countries", European Economic Review, vol. 49, no. 6, 1543-1569.

[17] Dolado, J.J., J.D. López-Salido and J.L. Vega (2000): "Unemployment and inflation persistence in Spain: are there Phillips tradeoffs?", Spanish Economic Review, vol. 2, no. 3, 267-291. 
[18] Estrella, A. and Mishkin, F. (1996): "The yield curve as a predictor of US recessions", Current Issues in Economics and Finance, vol. 2, no. 7, 1-6.

[19] Estrella, A. and Mishkin, F. (1997): "Is there a role for monetary aggregates in the conduct of monetary policy?", Journal of Monetary Economics, vol. 40, no. 2, 279-304.

[20] Favara, G. and P. Giordani (2009): "Reconsidering the role of money for output, prices and interest rates", Journal of Monetary Economics, vol. 56, no. 3, 419-430.

[21] Fisher, M.E. and J.J. Seater (1993): "Long-run neutrality and supeneutrality in an ARIMA framework", The American Economic Review, vol. 83, no. 3, 402-415.

[22] Karanassou, M. and Sala, H. (2008): "Productivity growth and the Phillips curve: a reassessment of the US experience", in School of Economics Discussion Paper, 2008/06, University of New South Wales, Sydney.

[23] Karanassou, M. and Sala, H. (2009): Labour market dynamics in Australia: what drives unemployment? in IZA Discussion Papers, 3924, Bonn.

[24] Karanassou, M., H. Sala and D.J. Snower (2003): "The European Phillips Curve: Does the NAIRU Exist?", Applied Economics Quarterly, vol. 49, no. 3, 93-121.

[25] Karanassou, M., H. Sala and D.J. Snower (2005): "A reappraisal of the inflationunemployment trade-off", European Journal of Political Economy, vol. 21, no. 1, 1-32.

[26] Karanassou, M., H. Sala and D.J. Snower (2008a): "Long-run inflation-unemployment dynamics: The Spanish Phillips curve and economic policy", Journal of Policy Modeling, vol. 30, no. 2, 279-300.

[27] Karanassou, M., H. Sala and D.J. Snower (2008b): "The evolution of inflation and unemployment: explaining the roaring nineties", Australian Economic Papers, vol. 47, no. 4, 334-354.

[28] Karanassou, M., H. Sala and D.J. Snower (2009): "Phillips curves and unemployment dynamics: a critique and a holistic perspective", Journal of Economic Surveys, forthcoming.

[29] Klein, L.R. and Ball, R.J. (1959): "Some econometrics of the determination of absolute prices and wages", The Economic Journal, vol. 69, no. 275, 465-482

[30] Leeper, E.M., Sims, C.A., and T. Zha (1996): "What does monetary policy do?", Brookings Papers on Economic Activity, vol. 1996, no. 2, 1-78.

[31] Mankiw, N.G. (2001): "The inexorable and mysterious tradeoff between inflation and unemployment," The Economic Journal, vol. 111, no. 471, C45-C61.

[32] Mankiw, N.G. and R. Reis (2002): "Sticky information versus sticky prices: a proposal to replace the New Keynesian Phillips curve" ,The Quarterly Journal of Economics, vol. 117, no. $4,1295-1328$.

[33] Nelson, E. (2003): "The future of monetary aggregates in monetary policy analysis", Journal of Monetary Economics, vol. 50, no. 5, 1029-1059.

[34] Nelson, E. (2007): "Comment on: Samuel Reynard, <Maintaining low inflation: money interest rates, and policy stance〉", Journal of Monetary Economics, vol. 54, no. 5, 1472-1479.

[35] Nelson, E. (2008): "Why money growth determines inflation in the long-run: answering the Woodford critique", Journal of Money, Credit and Banking, vol. 40, no. 8, 1791-1814. 
[36] Qin, D. (2008): "Rise of var modelling approach", mimeo. (Previous version in Discussion Paper Series, 557, Economics Department, Queen Mary University of London, 2006).

[37] Raddatz, C., and R. Rigobon (2003): Monetary policy and sectoral shocks: did the Fed react properly to the high-tech crisis? in NBER Working Paper, 9835, New York.

[38] Reynard, S. (2007): "Maintaining low inflation: money, interest rates, and policy stance", Journal of Monetary Economics, vol. 54, no. 5, 1441-1471.

[39] Ribba, A. (2006): "The joint dynamics of inflation, unemployment and interest rate in the United States since 1980", Empirical Economics, vol. 31, no. 2, 497-511.

[40] Ribba, A. (2007): "Permanent disinflationary effects on unemployment in a small open economy: Italy 1979-1995", Economic Modelling, vol. 24, no. 1, 66-81.

[41] Rudebusch, G.D. (1998): “Do measures of monetary policy in a var make sense?", International Economic Review, vol. 39, no. 4, 907-931.

[42] Sargan, J.D. (1964): "Wages and prices in the United Kingdom: a study in econometric methodology", pp. 25-59, in Hart, P.E., Mills, G., and Whitaker, J.K. (eds.), Econometric Analysis for National Economic Planning, London: Butterworths.

[43] Sims, C.A. (1992): "Interpreting the macroeconomic time series facts: the effects of monetary policy", European Economic Review, vol. 36, no. 5, 975-1011.

[44] Spanos, A. (1990): "The simultaneous-equations model revisited: statistical adequacy and identification", Journal of Econometrics, vol. 44, no. 1-2, 87-105.

[45] Staiger, D. and J. Stock (1997): "Instrumental variables regression with weak instruments", Econometrica, vol. 65, no. (3), 577-586.

[46] Stiglitz, J.E. (2003): The Roaring Nineties, New York, W.W. Norton \& Company.

[47] Stock, J. and M. Watson (2001): "Vector autoregressions", Journal of Economic Perspectives, vol. 15 , no. $4,101-115$.

[48] Woodford, M. (2003): Interest and Prices: Foundations of a Theory of Monetary Policy, Princeton University Press, Princeton, NJ.

[49] Woodford, M. (2008): "How important is money in the conduct of the monetary policy?", Journal of Money, Credit and Banking, vol. 40, no. 8, 1561-1598.

[50] Woodford, M. (2009): "Convergence in macroeconomics: elements of the new synthesis", American Economic Journal: Macroeconomics, vol. 1, no. 1, 267-279. 